\title{
Artificial neural network modelling of macrophyte indices based on physico-chemical characteristics of water
}

\author{
Daniel Gebler • Dariusz Kayzer • \\ Krzysztof Szoszkiewicz • Anna Budka
}

Received: 4 December 2012/ Accepted: 2 June 2013/Published online: 25 July 2013

(C) The Author(s) 2013. This article is published with open access at Springerlink.com

\begin{abstract}
The study focused on modelling of macropyte indices against physico-chemical parameters of waters by artificial neural networks. Several macrophyte diversity indices were analysed (species richness- $N$, the Shannon index- $H^{\prime}$, the Simpson index $-D$, and the Pielou index- $-J$ ) as well as the ecological status index (the Macrophyte Index for Rivers-MIR). The aim of the study was to verify knowledge about potential application of macrophytes in the environmental monitoring. A Multi-Layer Perceptron type of network was used in the analyses. The study included 260 river sites located throughout Poland. Alkalinity, conductivity, $\mathrm{pH}$, nitrate and ammonium nitrogen, reactive and total phosphorus, and biochemical oxygen demand were used as the explanatory variables. The quality of the constructed
\end{abstract}

Guest editors: M. T. Ferreira, M. O’Hare, K. Szoszkiewicz \& S. Hellsten / Plants in Hydrosystems: From Functional Ecology to Weed Research

D. Gebler $(\bowtie) \cdot$ K. Szoszkiewicz

Department of Ecology and Environmental Protection, Poznan University of Life Sciences, Wojska Polskiego 28, 60-637 Poznan, Poland

e-mail: dgebler@up.poznan.pl

D. Kayzer · A. Budka

Department of Mathematical and Statistical Methods, Poznan University of Life Sciences, Wojska Polskiego 28, 60-637 Poznan, Poland models was assessed using calculated errors (RMSE and NRMSE) and $r$ Pearson's linear correlation coefficient. The neural network for the MIR index was characterised by the highest quality. Neural networks for other diversity indices $\left(N, H^{\prime}, D\right.$, and $J$ ) did not provide adequate results for modelling, which shows their ineffectiveness biological monitoring. Sensitivity analysis revealed the influence of each variable to the models. It indicated that modelled values of MIR are most strongly influenced by total phosphorus and alkalinity.

Keywords Artificial neural networks · Macrophytes · Water quality · Biological monitoring $\cdot$ Water framework directive

\section{Introduction}

River evaluation and classification by assessing their ecological status is an approach in monitoring required by the Water Framework Directive (WFD). Macrophytes belong to the groups of organisms considered by the WFD for river assessment. For the purpose of monitoring several systems based on aquatic plants have been developed, of which some have been integrated into national monitoring programs. Habitat evaluation based on macrophytes is associated with a number of physico-chemical characteristics of water quality, mainly nutrients (Holmes et al., 1999; Haury, 
1996; Schneider et al., 2000; Haury et al., 2006) and morphological degradation (O'Hare et al., 2006). Recently some approaches in monitoring have been critically examined and the existence of strong correlations between aquatic plants and several quality determinants has been disputed (Demars et al., 2012). Therefore macrophyte monitoring requires more support utilising new databases and implementing additional statistical techniques.

Advanced data analysis techniques, among which artificial neural networks have become particularly popular in recent years, and have been increasingly used in interpreting the results of environmental research (Gabriels et al., 2007; Iliadis \& Maris, 2007; Samecka-Cymerman et al., 2009; Gevrey et al., 2010; Penczak et al., 2012). Statistical programs that are based on artificial neural networks are applicable where traditional methods of data analysis do not provide satisfactory results (Lencioni et al., 2007; Palialexis et al., 2011). ANNs are non-linear modelling tools based on a biological neuron structures and the human brain processes. A considerable advantage of ANNs is that they can have various structure and they involve various interactive algorithms depending on the problem investigated. This considerably extends their applicability in solving complex relationships which are faced in ecosystem analysis (Lek \& Guégan, 1999; Lek et al., 2000; Özesmi et al., 2006).

Artificial neural networks have been utilised for several applications in research of different types of surface waters, both inland (Singh et al., 2009; He et al., 2011) and marine waters (Lee et al., 2003; Millie et al., 2012). These techniques have frequently been used for major groups of aquatic organisms, i.e., fish (Suryanarayana et al., 2008; Penczak et al., 2012), macroinvertebrates (Lencioni et al., 2007; Kim et al., 2008), algae (Lee et al., 2003; Jeong et al., 2006) whereas macrophyte data have been treated by ANNs relatively rarely (Samecka-Cymerman et al., 2007). Neural networks introduced new aspects into analyses of relationships between organisms and their habitat. It was the purpose of this study to broaden the knowledge of the indicative value of macrophytes by introducing artificial neural networks in modelling. The application of this technique is limited in aquatic plant ecology research. In our study we modelled several macrophyte indices against physico-chemical parameters of water.

\section{Methods and materials}

Field surveys

The surveys on aquatic plants were carried out on 260 river sites located throughout Poland. Different river types were considered including lowland, highland and mountain rivers. Analysed rivers cover a wide range of hydromorphological degradation.

The research was based on the Polish method used in the national monitoring utilising the Macrophyte Index for Rivers (MIR) (Szoszkiewicz et al., 2010). It involves a quantitative and qualitative inventory of all species growing within a $100-\mathrm{m}$ reach of a river. Species cover abundance was assessed with a 9-point scale (Table 1).

The MIR was calculated with the following formula (Szoszkiewicz et al., 2010):

$\operatorname{MIR}=\frac{\sum_{i=1}^{N}\left(L_{i} \cdot W_{i} \cdot P_{i}\right)}{\sum_{i=1}^{N}\left(W_{i} \cdot P_{i}\right)} \cdot 10$

where MIR value of the Macrophyte Index for Rivers at the sampling site, $N$ number of species at the sampling site, $P_{i}$ ratio of coverage for $i$-th taxon, $W_{i}$ weighting factor for $i$-th taxon, and $L_{i}$ indicator value for $i$-th taxon.

The lower the MIR value, the more degraded the watercourse in terms of its trophic status. MIR values range from 10 for eutrophic rivers up to 100 for rivers with the best ecological status.

Based on the data collected in the field, in addition to the MIR index, four other macrophyte metrics (diversity indices) were calculated, i.e., the number of species $(N)$, the Shannon index (Shannon \& Weaver,

Table 1 The scale of sampling surface coverage by species used to calculate various metrics

\begin{tabular}{ll}
\hline Surface coverage $(\%)$ & $\left(P_{i}\right)[i=1, \ldots, N]$ \\
\hline$<0.1$ & 1 \\
$0.1-1$ & 2 \\
$1-2.5$ & 3 \\
$2.5-5$ & 4 \\
$5-10$ & 5 \\
$10-25$ & 6 \\
$25-50$ & 7 \\
$50-75$ & 8 \\
$>75$ & 9 \\
\hline
\end{tabular}


$1949, H^{\prime}$ ), the Simpson index (Simpson, 1949, D) and evenness (Pielou, 1969, J).

Water samples for analyses of physico-chemical parameters were also collected during the field surveys. For each sampling site, 8 parameters were identified: alkalinity, conductivity, reactive and total phosphorus, nitrate and ammonia nitrogen, $\mathrm{pH}$ and biochemical oxygen demand.

\section{ANN modelling}

All the botanical and physico-chemical data were used in the artificial neural network modelling. The results of the analyses of water samples were used as modelling variables to the constructed networks, and the macrophyte metrics were used as output modelled variables (Fig. 1). Automated neural networks available in STATISTICA 9.1 (StatSoft, Inc., 2010) were used for the statistical analyses. There are different ranges of values between analysed variables in terms of their means and standard deviations (Table 2). Ammonia nitrogen was characterised by the lowest values (mean $=0.35 \mathrm{mg} \mathrm{N}-\mathrm{NH}_{4} / \mathrm{dm}^{3}$ ), while the MIR it was the largest $($ mean $=46.6)$. Variables having relatively high values might dominate the model. Therefore, according to many recommendations (Lee et al., 2003; Nourani \& Fard, 2012) all input and output variables were standardised to improve the learning process of the neural network. Autoscaling, which provides the best results (Lek et al., 2000), was used in our investigation (Eq. 2) $z_{i}=\frac{x_{i}-\mu}{\sigma}$

where $x_{i} i$ th values of each variable (Alkal., Cond., $\mathrm{P}_{\text {react }}, \mathrm{P}_{\text {tot. }}$, Nitr., Ammon., $\mathrm{BOD}_{5}, \mathrm{pH} ; M I R N, H^{\prime}, D$, $J) ; z_{i} i$ th standardised value of the variable, $\mu$ mean of the variable, and $\sigma$ standard deviation of the variable.

To model all five macrophyte metrics, a multilayer perceptron type of network was used. It is a network trained with "a teacher" technique called the delta rule. This type of network is best known and most widely used in the practice of network topologies (Lek et al., 2000). The collected data, which consist of 260 cases, were divided into three sets. The first one (training set) contained 182 cases, while the second (validation set) and third (test set) contained over 39 cases each.

The root mean square error (RMSE) and normalised RMSE (NRMSE) were calculated to assess the usefulness of the models to estimate the MIR, based on physico-chemical parameters. The following equations were used:

$\mathrm{NRMSE}=\sqrt{\frac{\sum_{i=1}^{K}\left(\mathrm{MIR}_{O_{i}}-\mathrm{MIR}_{M_{i}}\right)^{2}}{K}}$

and

$\mathrm{NRMSE}=\frac{\mathrm{RMSE}}{\mathrm{MIR}_{\max }-\mathrm{MIR}_{\min }}$

where $K$ number of repetitions, $\mathrm{MIR}_{O_{i}} i$ th observed standardised values of the MIR, $\operatorname{MIR}_{M_{i}} i$ th

Table 2 Basic statistics of input and output variables

\begin{tabular}{|c|c|c|c|c|c|c|c|}
\hline Variable & Shortcode & Unit & Range & Mean & Median & SD & $\mathrm{CV}(\%)$ \\
\hline Alkalinity & Alkal. & $\mathrm{mg} \mathrm{CaCO} / \mathrm{dm}^{3}$ & $0.08-11.28$ & 2.95 & 2.70 & 1.77 & 60 \\
\hline Conductivity & Cond. & $\mathrm{mS} / \mathrm{cm}$ & $0.03-1.56$ & 0.46 & 0.38 & 0.29 & 63 \\
\hline Reactive phosphorus & $\mathrm{P}_{\text {react. }}$ & $\mathrm{mgPO}_{4} / \mathrm{dm}^{3}$ & $0.01-6.10$ & 0.48 & 0.27 & 0.78 & 163 \\
\hline Total phosphorus & $\mathrm{P}_{\text {tot. }}$ & $\mathrm{mgPO}_{4} / \mathrm{dm}^{3}$ & $0.02-7.85$ & 0.68 & 0.45 & 0.95 & 140 \\
\hline Nitrate nitrogen & Nitr. & $\mathrm{mg} \mathrm{N}-\mathrm{NO}_{3} / \mathrm{dm}^{3}$ & $0.02-9.00$ & 1.06 & 0.60 & 1.34 & 126 \\
\hline Ammonia nitrogen & Ammon. & $\mathrm{mg} \mathrm{N}-\mathrm{NH}_{4} / \mathrm{dm}^{3}$ & $0.01-7.75$ & 0.35 & 0.15 & 0.77 & 220 \\
\hline Biochemical oxygen demand & $\mathrm{BOD}_{5}$ & $\mathrm{O}_{2} \mathrm{mg} / \mathrm{dm}^{3}$ & $0.01-14.40$ & 2.60 & 2.20 & 1.83 & 70 \\
\hline $\mathrm{pH}$ & $\mathrm{pH}$ & & $4.25-9.03$ & 7.75 & 7.76 & 0.40 & 5 \\
\hline Macrophyte Index for River & MIR & - & $16.1-100$ & 46.6 & 40.7 & 17.2 & 37 \\
\hline Number of species & $\mathrm{N}$ & - & $1-52$ & 17 & 17 & 8 & 47 \\
\hline Shannon index & $\mathrm{H}^{\prime}$ & - & $0.00-2.85$ & 1.57 & 1.61 & 0.58 & 37 \\
\hline Simpson index & D & - & $0.00-0.92$ & 0.65 & 0.72 & 0.20 & 31 \\
\hline Evenness (Pielou index) & $\mathrm{J}$ & - & $0.00-1.00$ & 0.58 & 0.60 & 0.19 & 33 \\
\hline
\end{tabular}


standardised values of the MIR calculated by the model, $\mathrm{MIR}_{\min }$ minimum standardised value observed of the MIR, $\mathrm{MIR}_{\max }$ maximum standardised value observed of the MIR.

The quality of the constructed models was assessed using the NRMSE and also the $r$ Pearson's linear correlation coefficient between variables modelled by the networks and calculated on the basis of the botanical research. The same procedure was performed for macrophyte diversity indices: species richness, the Shannon index, the Simpson index, and the Pielou index. The best ANN model for each index was selected based on the highest $r$ value and the lower NRMSE values as determined for the testing dataset.

\section{Sensitivity analysis}

The impact of individual parameters for each model was evaluated using global sensitivity analysis. Sensitivity analysis is one of the explanatory methods, which assesses how "important" are the predictive variables for the neural network output (Gevrey et al., 2003). The value obtained for each input variable is the ratio, of the mean square error of the network without this variable, to the error of the network with a set of explanatory variables. The result shows how much the error of the network will increase if a particular variable is removed from the model. The variables yielding in the analysis values close to or lower than one would not contribute relevant information to the network (StatSoft, Inc. 2010).

\section{Results}

Modelling of the five macrophyte indices was conducted using artificial neural networks. Different structures of the optimal models were developed for each index (Table 3). The models had the same number of layers (3). Input and output layers correspond to input and output variables, respectively. The number of neurons in hidden layers varied, which resulted from the essence of the learning process of artificial neural networks, in which the network structure is refined, e.g., using iterative algorithms, in order to minimize the error (Amirikian, 2009). Parameters determining the quality of prediction of the three processes of constructing the model were calculated for each artificial neural network (Table 3).

Parameters defining the quality of the models at various stages of network structure optimisation were calculated for the obtained neural networks (Table 3). Both Pearson's correlation coefficient $(r)$ between the observed and modelled values and the normalised mean square error indicates a better modelling network performance for MIR rather than for the other macrophyte diversity indices investigated. The correlation coefficient for the MIR testing set was 0.841 (the empirical significance level is lower than 0.01 ) and the NRMSE was $14.1 \%$, which indicates accurate prediction of this index value.

When comparing values of estimated parameters of the obtained neural networks it resulted in correlation coefficients for macrophyte diversity indices much lower than for MIR. Similarly, the NRMSE was higher for the indices when compared to MIR. The correlation coefficients for macrophyte diversity indices in the tested dataset ranged from 0.322 to 0.478 , whereas NRMSE ranged between 21.1 and $27.8 \%$.

It should be noted that the output variables were characterised by comparable values of the coefficient of variation (Table 2). CV for MIR was $37 \%$ and for diversity indices it ranged from $31 \%$ (Simpson index) to $47 \%$ (species richness). It follows that the

Table 3 Parameters of artificial neural networks for modelling of macrophyte indices

\begin{tabular}{|c|c|c|c|c|c|c|c|}
\hline \multirow[t]{2}{*}{ Model } & \multirow[t]{2}{*}{ ANN structure } & \multicolumn{3}{|l|}{$r(p)$} & \multicolumn{3}{|c|}{ RMSE (NRMSE) } \\
\hline & & Training & Validation & Testing & Training & Validation & Testing \\
\hline MIR & $8-4-1$ & $0.883(<0.01)$ & $0.883(<0.01)$ & $0.841(<0.01)$ & $0.461(9.9 \%)$ & $0.401(9.7 \%)$ & $0.623(14.1 \%)$ \\
\hline$N$ & $8-9-1$ & $0.542(<0.01)$ & $0.367(0.220)$ & $0.478(0.002)$ & $0.851(15.2 \%)$ & $0.838(15.9 \%)$ & $0.965(27.8 \%)$ \\
\hline$H^{\prime}$ & $8-10-1$ & $0.338(<0.01)$ & $-0.042(0.798)$ & $0.452(0.004)$ & $0.913(18.7 \%)$ & $1.065(22.9 \%)$ & $1.040(22.5 \%)$ \\
\hline$D$ & $8-7-1$ & $0.269(<0.01)$ & $0.176(0.284)$ & $0.322(0.046)$ & $0.905(19.9 \%)$ & $1.092(24.5 \%)$ & $1.108(24.4 \%)$ \\
\hline$J$ & $8-7-1$ & $0.345(<0.01)$ & $0.326(0.43)$ & $0.408(0.010)$ & $0.888(17.0 \%)$ & $1.088(21.8 \%)$ & $0.969(21.1 \%)$ \\
\hline
\end{tabular}

*p empirical significance level 


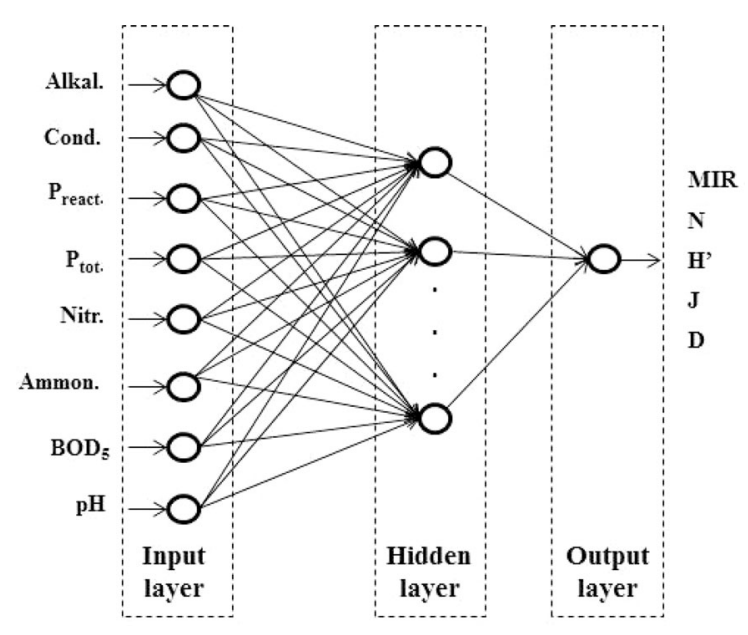

Fig. 1 The concept of artificial neural network for computation of five macrophyte indices

variability of the considered macrophyte metrics did not affect the quality of the obtained models.

These differences can also be observed in the scatterplots depicting a relation between observed values of the five considered macrophyte indices and their residuals (Fig. 2). The plots show a symmetrical distribution of values to a linear trend. The observed relationship between MIR values and residuals shows complete independence and random distribution $\left(R^{2}=0.191\right)$. For diversity indices $\left(N, H^{\prime}, D\right.$ and $J)$ the plots show a linear relationship between values of indices and the residuals $\left(R^{2}\right.$ ranges from 0.783 to 0.942). It shows insufficient fit of the constructed neural networks models to the data set.

Figures 3, 4, and 5 show a comparison of the modelled and observed values of the MIR in the three learning processes of the neural network. Prediction of the MIR value using the artificial neural network is relatively accurate. A constructed neural network does not very often predict extreme (minimum and maximum) values of the index. A precise estimation of output variable extreme values could indicate overfitting of a network, which is undesirable. The lowest NRMSE (below 10\%) was obtained in the training and validation processes of the network. Slightly higher errors (over $14 \%$ ) were obtained for testing of the network.

The sensitivity analysis shows a relationship between the development of aquatic vegetation and physicochemical factors (Table 4). It was demonstrated that the prediction model of MIR is primarily sensitive to changes in the concentration of total phosphorus in the water. The mean square error quotient of the network without the variable describing total phosphorus to the network error with all variables was 3.177. Alkalinity had almost the same impact on the modelled MIR value. Elimination of this variable from the network would increase the model error over three times (3.069). Subsequently, conductivity and total phosphorus also affect MIR, but in these two cases the increase of the network error is not so large. Other parameters have values close to one, which indicate no relevant information to the model.

The results of the sensitivity analysis of the networks for the four diversity indices confirm that modelling of values of these indices on the basis of physico-chemical parameters of the water is not feasible. Only conductivity showed some impact on model predictions of species richness. Sensitivity analysis values obtained for the other parameters are close to one. This indicates no relationship between aquatic vegetation diversity and water quality.

\section{Discussion}

The relationships and processes observed in ecological research are very often complex and non-linear, which substantially reduces the possibility of using classical regression methods (Lek et al., 2000; Gevrey et al., 2003). Non-linear methods of data analysis based on artificial intelligence were frequently used in many studies of freshwater ecosystems to provide insight into the variety of living organisms (Lencioni et al., 2007; Kim et al., 2008; Penczak et al., 2012). Therefore, in this study we have decided to use the model of artificial neural networks to investigate the relationship between aquatic plants (described by various macrophyte indices) and water quality. Application of sensitivity analysis facilitated more complete interpretation of the results, which is also indicated as an advantage of the networks (Özesmi et al., 2006; Nourani \& Fard, 2012).

A lack of a relationship between the four biodiversity indices and physico-chemical parameters of water indicates their uselessness in biological monitoring, which is also often reported in literature (Hering et al., 2006). However, we found that macrophytes may be still used for pollution detection, as it has been shown by the MIR model. This index using the specific reaction 
Fig. 2 A plot of observed macrophyte indices values and their residuals from modelling a the Macrophyte Index for River (Pielou index), $\mathbf{b}$ the number of species, $\mathbf{c}$ the Shannon index, $\mathbf{d}$ the Simpson index and e evenness
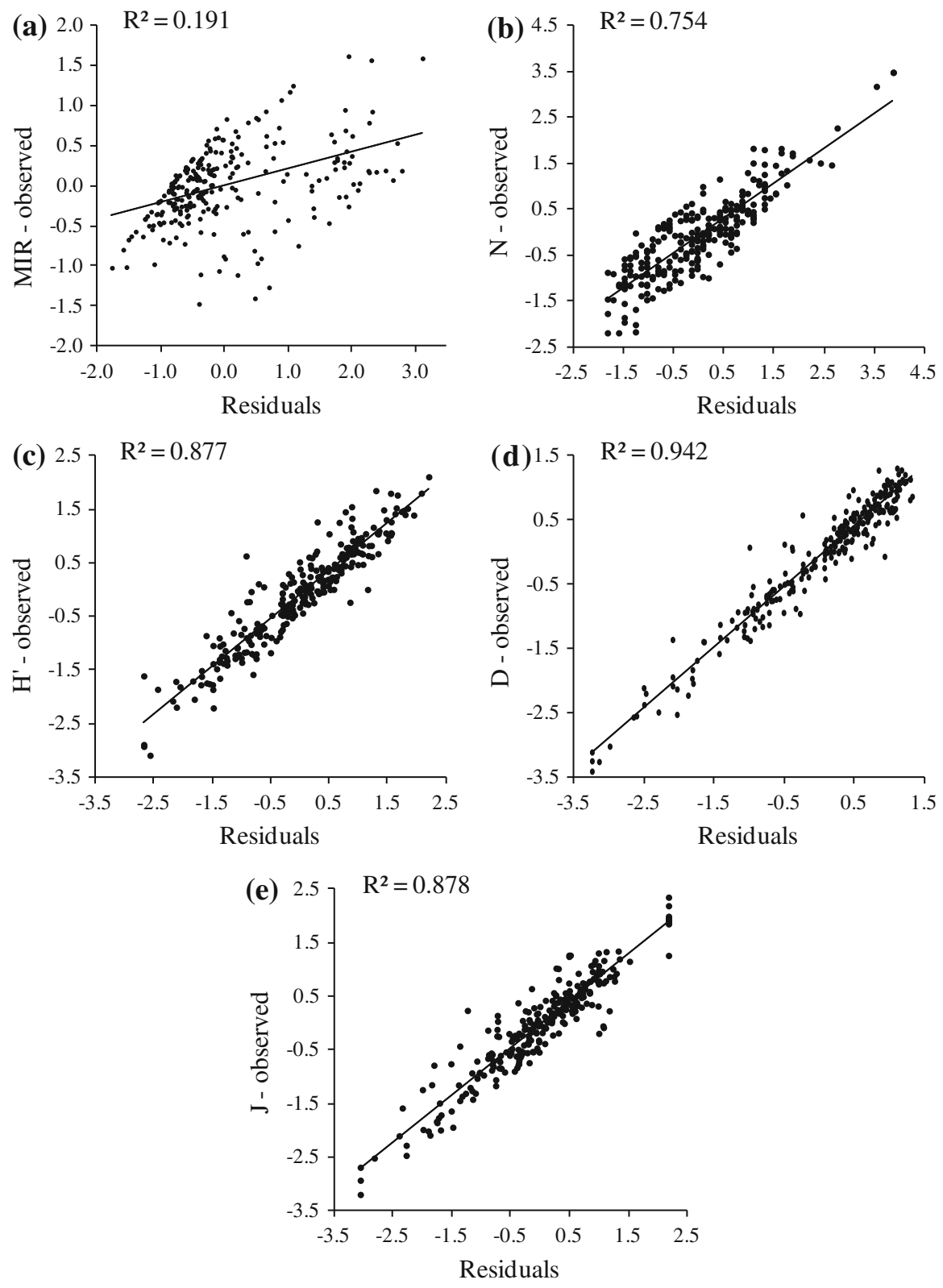

of individual taxa to pollution can be utilised to determine the state of the aquatic ecosystem. This approach has often been used in several currently applied bioindication systems for rivers, involving not only macrophytes, but also other groups of aquatic organisms (Haury et al., 2006; Willby et al., 2009; Feio et al., 2012).

The applicability of sensitivity analysis to assess the impact of each input variable on constructed neural network models is often shown in similar studies (Özesmi et al., 2006; Singh et al., 2009). The results of the sensitivity analysis correspond with other research on the impact of physico-chemical parameters, including nutrients, on the macrophyte metrics of river degradation (Dodkins et al., 2005; Haury et al., 2006; Hering et al., 2006; Szoszkiewicz et al., 2006). The identified major impact of mainly phosphorus and alkalinity on MIR shows the value of this index as an indicator of eutrophication, which was shown earlier by other authors (Szoszkiewicz et al., 2006).

Our results reveal a potential of the use of the macrophyte index to detect phosphorous which can 
Fig. 3 A comparison of modelled and observed MIR values (training set)

Fig. 4 A comparison of modelled and observed MIR values (validation set)

Fig. 5 A comparison of modelled and observed MIR values (testing set)
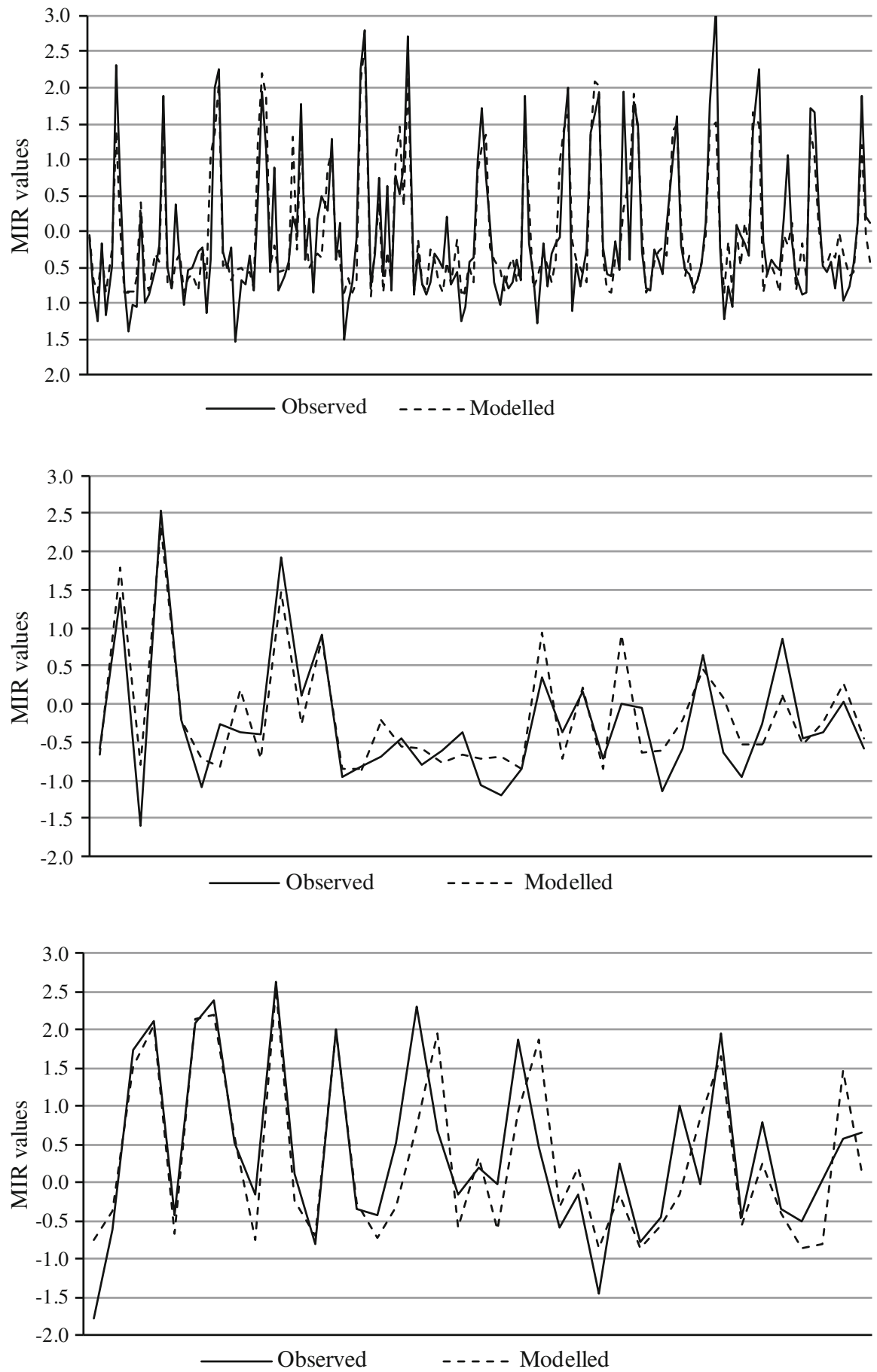

have an applications in the assessment of the ecological status for the Water Framework Directive purpose. It was argued in literature recently due to a weak correlation between nutrients and macrophyte indices (Demars \& Edwards, 2009). In our study prediction models based on artificial neural networks indicated a strong relationship between MIR and water quality variables, especially phosphorus concentration. However, data analysis techniques used in this study differ significantly from previously used (e.g., Dodkins 
Table 4 Sensitivity analysis of ANNs

\begin{tabular}{lllllllll}
\hline Parameter & $\mathrm{P}_{\text {tot }}$ & Alkal. & Cond. & $\mathrm{P}_{\text {react }}$ & $\mathrm{pH}$ & Ammon. & Nitr. & BOD \\
\hline MIR & 3.177 & 3.069 & 1.655 & 1.466 & 1.268 & 1.154 & 1.119 \\
Rank & $\mathbf{1}$ & $\mathbf{2}$ & $\mathbf{3}$ & $\mathbf{4}$ & 5 & 6 & 7 & 1.002 \\
$N$ & 1.029 & 1.139 & 1.446 & 1.087 & 1.115 & 1.000 & 1.013 \\
Rank & 5 & 2 & $\mathbf{1}$ & 4 & 3 & 8 & 7 & 1.007 \\
$H^{\prime}$ & 0.993 & 1.201 & 1.083 & 1.000 & 1.023 & 1.015 & 0.998 \\
Rank & 8 & 1 & 2 & 6 & 3 & 4 & 1.004 \\
$D$ & 1.007 & 1.127 & 1.068 & 1.005 & 1.020 & 1.011 & 7 \\
Rank & 6 & 1 & 2 & 7 & 3 & 4 & 1.002 \\
$J$ & 1.004 & 1.168 & 1.123 & 1.041 & 1.010 & 1.019 & 8 & 1.011 \\
Rank & 8 & 1 & 2 & 5 & 7 & 6 & 4 \\
\hline
\end{tabular}

et al., 2005; Demars \& Edwards, 2009). Artificial neural networks are based on the analysis of non-linear functions, whereas other methods use eigenvalues and eigenvectors generated by linear models. The use of neural networks allowed us to examine the relationships between macrophytes and water quality in a different way, which is based on the collective signal (not cumulative) of the complex physical and chemical parameters.

The obtained range of the NRMSE for the MIR model $(14.1 \%)$ and range of the correlation coefficient can be regarded as satisfactory to prove the relationship between macrophytes and physico-chemical parameters. The level of model quality was often higher in other studies, as for instance in river water quality modelling (Singh et al., 2009) or plant sciences (Gago et al., 2010).

Nevertheless the processes in the aquatic ecosystems which were analysed by us are known as extremely variable. Moreover macrophytes deliver a signal of the long-term ecological processes, whereas the hydrochemical parameters indicate momentary status of the water. The prediction capability in our model, which was lower than $20 \%$ can be regarded as acceptable.

The analyses showed a particularly strong role of phosphorus in the development of aquatic plants, whereas the influence of this element was difficult to distinguish from other correlated parameters, most often conductivity (Szoszkiewicz et al., 2006; Demars $\&$ Edwards, 2009). ANN application facilitates precise non-cumulative assessment of the impact of each predictor on the explanatory variable, which may be an indicative value of the macrophyte index, based on an indicative quantity of individual values taxa.
The undertaken analyses focused on the MIR, which is used mostly in Poland in the national monitoring for the purpose of the Water Framework Directive. However, analysis of the MIR may provide information on the potential applicability of macrophyte methods in any country. The MIR is relevant to many other European indices such as IBMR (Haury et al., 2006) used in France, Wallonia and Mediterranean Europe, MTR (Holmes et al., 1999) which was used for years in the UK and was tested in many other countries, and RNMI (Willby et al., 2009) which is under implementation in the UK. These methods are based on the single metric combining occurrence (indicator value per taxon) and abundance and they differ only in a limited number of indicator taxa, which take account of local aquatic flora. Some of the indices differ in the abundance scale used in the field survey, but this element does not have a strong influence. Moreover, MIR was intercalibrated with other European indices within the Pan-European intercalibration exercise (Birk \& Willby, 2010). The results on the applicability of some macrophyte metrics for river monitoring can therefore be extensively used with respect to the interpretation of macrophyte assessment used in most EU countries.

\section{Conclusions}

We proved that modelling of the macrophyte quality index (MIR) based on physico-chemical parameters is possible with the use of artificial neural networks.

Results of the modelling show ineffectiveness of biodiversity indices $\left(N, H^{\prime}, D\right.$, and $\left.J\right)$ in biological 
monitoring because of the weak relationship with environmental variables, in this case with physicochemical parameters of the water.

We confirmed that there is a relationship between MIR and the concentration of phosphorous in water and water alkalinity.

We confirmed that the ecological status index (the MIR) can be applied in river monitoring to detect specific degradation of aquatic ecosystems.

Acknowledgments Daniel Gebler is a scholarship holder within the project "Scholarship support for Ph.D. students specializing in majors strategic for Wielkopolska's development", Sub-measure 8.2.2 Human Capital Operational Programme, co-financed by European Union under the European Social Fund. This paper is a result of two grants supported by the Ministry of Science and Higher Education (N305 145839 and N305 226033).

Open Access This article is distributed under the terms of the Creative Commons Attribution License which permits any use, distribution, and reproduction in any medium, provided the original author(s) and the source are credited.

\section{References}

Amirikian, B., 2009. Artificial neural networks. In Binder, M. D., N. Hirokawa \& U. Windhorst (eds), Encyclopedia of Neuroscience. Springer, Berlin: 181-185.

Birk, S. \& N. Willby, 2010. Towards harmonization of ecological quality classification: establishing common grounds in European macrophyte assessment for rivers. Hydrobiologia 652: 149-163.

Demars, B. O. L. \& A. C. Edwards, 2009. Distribution of aquatic macrophytes in contrasting river systems: a critique of compositional-based assessment of water quality. Science of the Total Environment 407(2): 975-990.

Demars, B.O.L., J. M. Potts, M. Tremolieres, G. Thiebaut, N. Gougelin \& V. Nordmann, 2012. River macrophyte indices: not the Holy Grail! Freshwater biology 57: 1745-1759.

Dodkins, I., B. Rippey \& P. Hale, 2005. An application of canonical correspondence analysis for developing ecological quality assessment metrics for river macrophytes. Freshwater Biology 50: 891-904.

Feio, M. J., F. C. Aguiar, S. F. P. Almeida \& M. T. Ferreira, 2012. AQUAFLORA: a predictive model based on diatoms and macrophytes for streams water quality assessment. Ecological Indicators 18: 586-598.

Gabriels, W., P. L. M. Goethals, A. P. Dedecker, S. Lek \& N. De Pauw, 2007. Analysis of macrobenthic communities in Flanders, Belgium, using a stepwise input variable selection procedure with artificial neural networks. Aquatic Ecology 41: 427-441.

Gago, J., M. Landin \& P. P. Gallego, 2010. Strengths of artificial neural networks in modelling complex plant processes. Plant Signaling \& Behavior 5(6): 743-745.
Gevrey, M., I. Dimopoulos \& S. Lek, 2003. Review and comparison of methods to study the contribution of variables in artificial neural network models. Ecological Modelling 160: 249-264.

Gevrey, M., L. Comte, D. de Zwart, E. de Deckere \& S. Lek, 2010. Modeling the chemical and toxic water status of the Scheldt basin (Belgium), using aquatic invertebrate assemblages and an advanced modeling method. Environmental Pollution 158: 3209-3218.

Haury, J., 1996. Assessing functional typology involving water quality, physical features and macrophytes in a Normandy river. Hydrobiologia 340: 43-49.

Haury, J., M.-C. Peltre, M. Trémolières, J. Barbe, G. Thiébaut, I. Bernez, H. Daniel, P. Chatenet, G. Haan-Archipof, S. Muller, A. Dutartre, C. Laplace-Treyture, A. Cazaubon \& E. Lambert-Servien, 2006. A new method to assess water trophy and organic pollution-the Macrophytes Biological Index for Rivers (IBMR): its application to different types of river and pollution. Hydrobiologia 570: 153-158.

He, B., T. Oki, F. Sun, D. Komori, S. Kanae, Y. Wang, H. Kim \& D. Yamazaki, 2011. Estimating monthly total nitrogen concentration in streams by using artificial neural network. Journal of Environmental Management 92: 172-177.

Hering, D., R. K. Johnson, S. Kramm, S. Schmutz, K. Szoszkiewicz \& P. F. M. Verdonschot, 2006. Assessment of European rivers with diatoms, macrophytes, invertebrates and fish: a comparative metric-based analysis of organism response to stress. Freshwater Biology 51: 1757-1785.

Holmes, N. T. H., J. R. Newman, S. Chadd, K. J. Rouen, L. Saint \& F. H. Dawson, 1999. Mean Trophic Rank: A user's manual. R\&D Technical Report E38, Environment Agency of England \& Wales, Bristol.

Iliadis, L. S. \& F. Maris, 2007. An artificial neural network model for mountainous water-resources management: the case of Cyprus mountainous watersheds. Environmental Modelling \& Software 22: 1066-1072.

Jeong, K. S., D. K. Kim \& G. J. Joo, 2006. River phytoplankton prediction model by artificial neural network: model performance and selection of input variables to predict timeseries phytoplankton proliferations in a regulated river system. Ecological Informatics 1: 235-245.

Kim, B., S. E. Lee, M.-Y. Song, J. H. Choi, S. M. Ahn, K. S. Lee, E. Cho, T. S. Chon \& S. C. Koh, 2008. Implementation of artificial neural networks (ANNs) to analysis of inter-taxa communities of benthic microorganisms and macroinvertebrates in a polluted stream. Science of Total Environment 390: 262-274.

Lee, J. H. W., Y. Huang, M. Dickman \& A. W. Jayawardena, 2003. Neural network modelling of coastal algal blooms. Ecological Modelling 159: 179-201.

Lek, S. \& J. F. Guégan, 1999. Artificial neural networks as a tool in ecological modelling, an introduction. Ecological Modelling 120: 65-78.

Lek, S., J. L. Giraudel \& J. F. Guegan, 2000. Neural networks: algorithms and architectures for ecologists and evolutionary ecologists. In Lek, S. \& J. F. Guegan (eds), Artificial Neural Networks. Application to Ecology and Evolution. Springer, Berlin: 3-27.

Lencioni, V., B. Maiolini, L. Marziali, S. Lek \& B. Rossaro, 2007. Macroinvertebrate assemblages in glacial stream systems: a comparison of linear multivariate methods with artificial neural networks. Ecological Modelling 203: 119-131. 
Millie, D. F., G. R. Weckmand, W. A. Young II, J. E. Ivey, H. J. Carrick \& G. L. Fahnenstiel, 2012. Modeling microalgal abundance with artificial neural networks: demonstration of a heuristic 'Grey-Box' to deconvolve and quantify environmental influences. Environmental Modelling \& Software 38: 27-39.

Nourani, V. \& M. S. Fard, 2012. Sensitivity analysis of the artificial neural network outputs in simulation of the evaporation process at different climatologic regimes. Advances in Engineering Software 47: 127-146.

O'Hare, M., A. Baattrup-Pedersen, R. C. Nijboer, K. Szoszkiewicz \& T. Ferreira, 2006. Macrophyte communities of European streams with altered physical habitat. Hydrobiologia 566: 197-210.

Özesmi, S. L., C. O. Tan \& U. Özesmi, 2006. Methodological issues in building, training, and testing artificial neural networks in ecological applications. Ecological Modelling 1935: 83-93.

Palialexis, A., S. Georgakarakos, I. Karakassis, K. Lika \& V. D. Valavanis, 2011. Fish distribution predictions from different points of view: comparing associative neural networks, geostatistics and regression models. Hydrobiologia 670: 165-188.

Penczak, T., Ł. Głowacki, A. Kruk \& W. Galicka, 2012. Implementation of a self-organizing map for investigation of impoundment impact on fish assemblages in a large, lowland river: long-term study. Ecological Modelling 227: 64-71.

Pielou, E. C., 1969. An introduction to mathematical ecology. Wiley-Interscience, New York.

Samecka-Cymerman, A., A. Stankiewicz, K. Kolon \& A. J. Kempers, 2007. Self-organizing feature map (neural networks) as a tool in classification of the relations between chemical composition of aquatic bryophytes and types of streambeds in the Tatra national park in Poland. Chemosphere 67: 954-960.
Samecka-Cymerman, A., A. Stankiewicz, K. Kolon \& A. J. Kempers, 2009. Self-organizing feature map (neural networks) as a tool to select the best indicator of road traffic pollution (soil, leaves or bark of Robinia pseudoacacia L.). Environmental Pollution 157: 2061-2065.

Schneider, S., T. Krumpholz \& A. Melzer, 2000. Trophäeindikation in Fliessgewässern mit Hilfe des TIM (TrophäeIndex Macrophyten)_Erprobung eines neu entwickelten Index im Inniger Bach. Acta Hydrochimica et Hydrobiologica 28: 241-249.

Shannon, C. E. \& W. Weaver, 1949. The Mathematical Theory of Communication. University of Illinois Press, Urbana.

Simpson, E. H., 1949. Measurement of diversity. Nature 163: 688.

Singh, K. P., A. Basant, A. Malik \& G. Jain, 2009. Artificial neural network modeling of the river water quality - a case study. Ecological Modelling 220: 888-895.

StatSoft, Inc., 2010. STATISTICA (data analysis software system), version 10 .

Suryanarayana, I., A. Braibanti, R. Sambasiva Rao, V. Anantha Ramam, D. Sudarsan \& G. Nageswara Rao, 2008. Neural networks in fisheries research. Fisheries Research 92: 115-139.

Szoszkiewicz, K., T. Ferreira, T. Korte, A. Baattrup-Pedersen, J. Davy-Bowker \& M. O'Hare, 2006. European river plant communities: the importance of organic pollution and the usefulness of existing macrophyte metrics. Hydrobiologia 566: $211-234$.

Szoszkiewicz, K., J. Zbierska, S. Jusik \& T. Zgoła, 2010. Makrofitowa Metoda Oceny Rzek. Podręcznik metodyczny do oceny i klasyfikacji stanu ekologicznego wód płynących w oparciu o rośliny wodne. Boguski Wydawnictwo Naukowe, Poznań. (in Polish).

Willby, N., J.-A. Pitt, \& G. Phillips, 2009. The Ecological Classification of UK Rivers Using Aquatic Macrophytes. Environment Agency, Science Report. 